\title{
Rapid rehabilitation nursing in postoperative patients with colorectal cancer and quality of life
}

\author{
FANG XU ${ }^{1 *}$, PEIPEI $\mathrm{YU}^{2 *}$ and $\mathrm{LI} \mathrm{LI}^{3}$ \\ ${ }^{1}$ Department of Rheumatic Nephrology; ${ }^{2}$ Vasculocardiology Department and ${ }^{3}$ General Department, \\ The Central Hospital of Wuhan, Tongji Medical College, Huazhong University \\ of Science and Technology, Wuhan, Hubei 430000, P.R. China
}

Received September 28, 2018; Accepted May 8, 2019

DOI: $10.3892 / \mathrm{ol} .2019 .10379$

\begin{abstract}
This study investigated the application of rapid rehabilitation nursing in postoperative patients with colorectal cancer (CRC) and its effect on quality of life (QOL). A prospective analysis was performed on 154 patients with CRC, after radical resection in The Central Hospital of Wuhan from February 2011 to April 2015. During the perioperative period, 96 patients (study group) received fast-track surgery (FTS) and 58 patients (control group) received routine surgery. The postoperative data of patients in the two groups were analyzed in terms of the first anus exhaustion time, the first time getting out of bed, first time eating liquid food, first defecation time, the time of drainage tube removal, time of gastric tube removal, time of suture removal, hospital stay and surgical expenses. Visual Analogue Scale (VAS) was used to assess postoperative pain. The re-hospitalization rate, the incidence of complications 30 days after operation, the survival and QOL scores were analyzed. After discharge patients were followed up for 3 years to observe the 3 -year overall survival (OS). VAS scores were lower in the study group than that in the control group at $6,12,24,48$ and $72 \mathrm{~h}$ after operation $(\mathrm{P}<0.05)$. The re-hospitalization rate and incidence of complications 30 days after operation were lower in the study group than those in the control group $(\mathrm{P}<0.05)$. Before nursing, there was no statistically significant difference in QOL score between the two groups $(\mathrm{P}>0.05)$, whereas after 3 and 12 months of nursing, QOL score was significantly higher in the study group than that in the control group $(\mathrm{P}<0.05)$. QOL score in the two groups increased with time, and there were differences between the two groups at each time-point $(\mathrm{P}<0.05)$. There
\end{abstract}

Correspondence to: Dr Li Li, General Department, The Central Hospital of Wuhan, Tongji Medical College, Huazhong University of Science and Technology, 26 Shengli Road, Wuhan, Hubei 430000, P.R. China

E-mail: d3534w@163.com

${ }^{*}$ Contributed equally

Key words: fast-track surgery, radical resection of colorectal cancer, quality of life, perioperative period was no significant difference in the 3 -year OS between the two groups $(\mathrm{P}>0.05)$. In conclusion, effectively improving patients' psychological state, reducing complications and relieving pain, the FTS during the perioperative period of CRC surgery promotes postoperative rehabilitation, reduces economic pressures and improves QOL.

\section{Introduction}

Colorectal cancer (CRC), the most common malignant tumor of the digestive tract (1), occurs mostly in countries with low educational level and poor quality of life (QOL), especially in people with unhealthy living and dietary habits (2). With the development of technology and economy, people's pace of life is getting faster, but the QOL gradually declines. In recent years, the incidence of CRC has increased steadily, accounting for $>15 \%$ of the systemic malignant tumors (4), and the age of onset has become younger (3), which is mostly 50-60 years (5). CRC has a high mortality rate, which seriously threatens people's life.

QOL is a medical professional concept comprising social, psychological and material fields (6), which was not valued in the beginning because of limited medical conditions. However, with the development of modern medicine and the changes in the treatment of tumors, killing tumor cells, reducing tumor diameter and improving tumor differentiation while ameliorating patients' mental state have become crucial (7). Most patients believe that the treatment is unsuccessful if it causes severe adverse reactions and even affects QOL (8). QOL mainly determines the bodily functions (discomfort, fatigue, sleep quality and sensory function), the psychological state (effects of negative emotions on themselves, on self-confidence, and on learning, memory, thinking and cognitive ability), the independent ability of daily living, social relations, interpersonal relationships, social returns and the environment (work environment, family environment, property resources and physical safety) (9).

In recent years, fast-track surgery (FTS) concept has been strongly promoted in developed countries of Europe and America (10). It refers to carrying out optimized treatment measures on patients during the perioperative period based on medical theory, in order to reduce the surgical stress response of the body (11). The treatment involves surgeons-in-charge, 
anesthesiologists, nurses, ICU physicians, dieticians, rehabilitation therapists, psychological counselors, family members, relatives and friends (12). According to a study, FTS shortens hospital stay, reduces postoperative complications and hospital cost, and increases inpatient satisfaction (13).

With the improvement of surgery and multi-element comprehensive treatment, such as radiotherapy and chemotherapy, patients with CRC are mainly treated with laparoscopy combined with radiotherapy and chemotherapy (14). Although the efficacy is improved and the radical rate is increased, the 5 -year survival rate after radical resection remains unsatisfactory at $\sim 60 \%$ (15). Additionally, multi-element comprehensive treatment causes adverse reactions, negatively affecting the patients' daily life, the psychological state and work ability (16). Therefore, identifying ways to improve the postoperative QOL of patients with CRC is imperative.

In this study, the application of FTS concept in patients with CRC and its effect on QOL were investigated regarding the safety and feasibility of FTS in promoting postoperative recovery, in order to provide a reference for clinical practice.

\section{Patients and methods}

Clinical baseline data. A prospective analysis was performed on 154 patients with CRC after radical resection in The Central Hospital of Wuhan from February 2011 to April 2015. All patients underwent colonoscopy before operation, and were pathologically diagnosed with CRC. According to patients' wishes and choices, 96 patients receiving FTS during the perioperative period served as the study group, including 36 males and 60 females, with a mean age of $55.38 \pm 15.12$ years; 58 patients receiving routine surgery served as the control group, including 24 males and 34 females, with a mean age of $56.17 \pm 15.81$ years.

Inclusion and exclusion criteria. Inclusion criteria: patients with a first-listed diagnosis with CRC; patients $\geq 18$ years of age; patients who received regular postoperative follow-up; patients who were willing to cooperate with the survey and completed the scale independently. All patients who participated in this research had complete clinical data. The study was approved by the Ethics Committee of The Central Hospital of Wuhan, Tongji Medical College, Huazhong University of Science and Technology (Wuhan, China). The patients and their family members were fully informed and signed a consent form.

Exclusion criteria: patients with recurrent CRC; patients with diabetes mellitus; patients with immune diseases; patients with cardiac-cerebral vascular diseases; patients with preoperative intestinal obstruction and hemorrhage.

\section{FTS concept}

Preoperative preparation. Three days before operation, psychological intervention was performed on patients, with the cooperation of family members and friends. The medical staff explained nursing knowledge, emergency measures and how to cooperate with the staff during the perioperative period. Before operation, the staff established a mutual trust relationship with patients to improve their compliance, and carried out psychological counseling to help patients handle preoperative pressure and the fear of operation. Patients were fasted for $6 \mathrm{~h}$ before operation, and were orally administered with $500 \mathrm{ml}$ of $10 \%$ glucose (Chongqing Daxin Pharmaceutical Co., Ltd.; PKU International Healthcare Group; SFDA approval no. H50021372) at $2 \mathrm{~h}$ before operation, which effectively reduced postoperative insulin resistance, preoperative hunger and psychological pressure. Nutritional Risk Screening (NRS) (17) was used for preoperative nutritional assessment. Patients with NRS score $\geq 3$ points were given nutritional support and were subjected to operation after the indicators reached the standard levels, whereas patients with NRS score $<3$ points were subjected to operation.

Intraoperative measures. Short-acting general anesthetics combined with short-acting regional block anesthetics were used during the operation. According to some scholars, this regimen is optimal because it prolongs the analgesic effect of drugs, reduces the postoperative stress response, and maintains the normal physiological function of patients. Liquid was strictly controlled during the operation, and a heating machine was used to maintain patients' normal body temperature, so as to prevent cardiac overload, water poisoning, cell edema and other symptoms.

Postoperative nursing. After operation, patients were given non-steroidal anti-inflammatory drugs and self-controlled analgesic mercury for preventing pain, and were intramuscularly injected with $40 \mathrm{mg}$ of parecoxib sodium (Pharmacia and Upjohn Co.; SFDA approval no. J20080045) for 3 consecutive days, twice daily. Patients carried out activities on the day of operation, got out of bed for $4 \mathrm{~h}$ on the 1st day after operation, and were also subjected to microwave treatment for abdominal operation. Low-power red laser (Red and blue light therapy apparatus, BH-3L; Beijing Zeao Medical Technology Co., Ltd.) was used to irradiate the incision area, which promoted the healing of the incision tissue, and a paste promoting intestinal tract movement was affixed to the navel. Patients drank water on the day of operation and ate liquid food on the 1st day after operation. Antibiotics were injected only on the 1st day after operation, and the bladder balloon was removed the next day.

Discharge standards. With regular exhaustion, patients could be discharged if they were fully active and free to eat ordinary food, with stable vital signs, good home environment and no obvious pain.

\section{Routine surgical concept}

Preoperative preparation. Patients ate liquid food 3 days before operation, fasted $12 \mathrm{~h}$ before operation and were also restricted from having water $8 \mathrm{~h}$ before surgery. At the same time, they were orally administered with laxative and subjected to clean enema.

Intraoperative measures. A nasogastric tube was inserted until the passage of gas by anus, and general anesthetics were used during the operation.

Postoperative nursing. After operation, dolantin (SFDA approval no. H63020170), morphine (SFDA approval no. H63020013) (both from Qinghai Pharmaceutical Co., Ltd.) and other opioid agents were used for analgesia, and patients 
Table I. Baseline data of patients in the study and the control group (n, mean \pm SD).

\begin{tabular}{|c|c|c|c|c|}
\hline Category & Study group $(n=96)$ & Control group $(\mathrm{n}=58)$ & $\chi^{2 / t}$ & P-value \\
\hline Sex & & & 0.229 & 0.733 \\
\hline Male & 36 & 24 & & \\
\hline Female & 60 & 34 & & \\
\hline Age (years) & $55.38 \pm 15.11$ & $56.17 \pm 15.81$ & 0.309 & 0.758 \\
\hline Body mass index $\left(\mathrm{kg} / \mathrm{m}^{2}\right)$ & & & 0.577 & 0.496 \\
\hline$<24$ & 57 & 38 & & \\
\hline$\geq 24$ & 39 & 20 & & \\
\hline Preoperative $\mathrm{Hb}$ (g/l) & $124.53 \pm 18.64$ & $122.48 \pm 20.21$ & 0.641 & 0.523 \\
\hline Preoperative Alb (g/l) & $41.23 \pm 3.42$ & $40.53 \pm 2.68$ & 1.331 & 0.185 \\
\hline Preoperative blood glucose (mmol/l) & $5.11 \pm 1.25$ & $5.21 \pm 1.03$ & 0.513 & 0.609 \\
\hline Preoperative CRP (mg/l) & $9.61 \pm 3.21$ & $10.22 \pm 3.91$ & 1.051 & 0.295 \\
\hline \multicolumn{5}{|l|}{ Tumor location } \\
\hline Left half & 12 & 8 & 0.053 & 0.810 \\
\hline Right half & 16 & 11 & 0.132 & 0.827 \\
\hline Sigmoid & 23 & 15 & 0.071 & 0.848 \\
\hline Rectum & 45 & 24 & 0.442 & 0.616 \\
\hline \multicolumn{5}{|l|}{ Tumor stage } \\
\hline I & 26 & 14 & 0.163 & 0.710 \\
\hline II & 41 & 26 & 0.066 & 0.867 \\
\hline III & 29 & 18 & 0.774 & 0.451 \\
\hline
\end{tabular}

drank water and ate after exhaustion. Before normal diet, intravenously infused nutrient solution was used as the nutritional support, and antibiotics were discontinued after patients' haemogram and body temperature returned to normal.

Discharge standards. Patients could be discharged if they took their own oral diet and were able to walk independently, without intravenous infusion of antibiotics.

\section{Observational indexes}

General information. Age, sex, body mass index, pathological staging, tumor location and other general baseline data were recorded.

Observational indexes of recovery. The postoperative data of patients in the two groups were analyzed in terms of the first anus exhaustion time, the first time getting out of bed (muscle strength $>4$, VAS $<3$, no discomfort in chief complaint), the first time eating liquid food (control group: after first defection; study group: 1st day after surgery), the first defecation time, time of drainage tube removal (control group: drainage $<10 \mathrm{ml} /$ day; study group: the 2 nd day after surgery), time of gastric tube removal (after first intake of liquid food), time of suture removal (wound healing level of 1), hospital stay and surgical expenses. Visual Analogue Scale (VAS) (18) was used to assess postoperative pain at 6 , $12,24,48$ and $72 \mathrm{~h}$ after operation. The re-hospitalization rate and incidence of complications (gastrointestinal dysfunction, intestinal anastomotic fistula, and wound infection) 30 days after operation, and survival were analyzed. After discharge, patients were followed up for 3 years to observe the 3 -year overall survival (OS).

Determination of QOL. The QOL measurement scale of patients with cancer, developed by the European Organization for Research on Treatment of Cancer, was used as the judgment basis (19). QOL before operation, at 3 and 12 months after nursing was assessed. Functional and symptom scales were included. Functional scale: physical function (PF), social function (SF), cognitive function (CF), role function (RF), and emotional function (EF). Symptom scale: constipation (CO), poverty (PO), insomnia disorder (ID), diarrhea (DI), dyspnea (DY), and anorexia (AN). The higher the functional and symptom scale scores were, the better the QOL was.

Interview methods. Surviving patients after discharge were interviewed by telephone. Patients who were extremely elderly, had poor communication, poor physical quality during the follow-up period were interviewed through return visit in patients' houses or consulting with relatives. The follow-up ended on April 2018, and the OS was calculated as the time from the 1st day after operation to the date of last follow-up or death.

Statistical analysis. In this study, SPSS 17.0 (SPSS, Inc.) software package was used to statistically analyze the data and generate the graphs. Enumeration data were expressed as rate $(\%)$ and tested by $\chi^{2}$ test. Measurement data were expressed as mean \pm standard deviation (mean $\pm \mathrm{SD}$ ), and tested by t-test. Independent samples t-test was used for comparisons between 
Table II. Comparison of postoperative basic indicators between the study and the control group (mean $\pm \mathrm{SD})$.

\begin{tabular}{|c|c|c|c|c|}
\hline Category & Study group $(n=96)$ & Control group $(n=58)$ & $\mathrm{t}$ & P-value \\
\hline First anus exhaustion time (h) & $51.12 \pm 7.41$ & $73.18 \pm 5.83$ & 19.340 & $<0.001$ \\
\hline First leaving-bed time (h) & $37.53 \pm 8.52$ & $62.48 \pm 9.62$ & 16.770 & $<0.001$ \\
\hline First eating-liquid food time (h) & $14.47 \pm 3.53$ & $48.53 \pm 6.23$ & 43.330 & $<0.001$ \\
\hline First defecation time (h) & $86.45 \pm 31.26$ & $112.74 \pm 41.24$ & 4.474 & $<0.001$ \\
\hline Time of drainage tube removal (h) & $4.56 \pm 1.22$ & $7.21 \pm 1.73$ & 11.120 & $<0.001$ \\
\hline Time of gastric tube removal (h) & $18.32 \pm 3.22$ & $97.72 \pm 40.17$ & 19.310 & $<0.001$ \\
\hline Time of suture removal (days) & $7.12 \pm 1.09$ & $8.46 \pm 1.98$ & 5.417 & $<0.001$ \\
\hline Postoperative hospital stay (days) & $9.46 \pm 0.63$ & $11.12 \pm 0.52$ & 16.880 & $<0.001$ \\
\hline Operation cost $\left(\mathrm{x} 10^{4} \mathrm{RMB}\right)$ & $4.73 \pm 0.84$ & $5.88 \pm 0.73$ & 8.638 & $<0.001$ \\
\hline
\end{tabular}

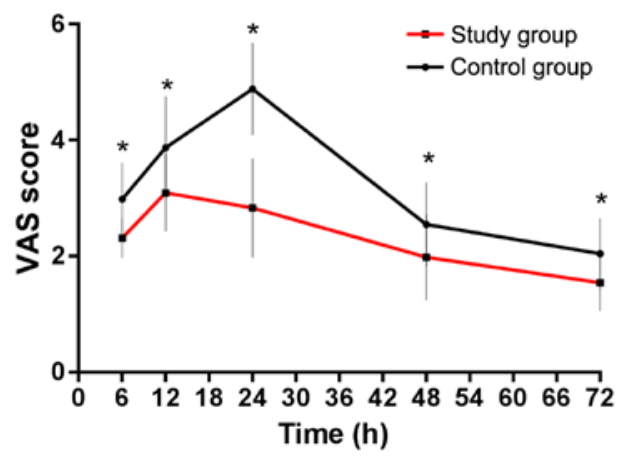

Figure 1. VAS score in the study group started to decrease at $12 \mathrm{~h}$ after operation, while in the control group it started to decrease at $24 \mathrm{~h}$ after operation. VAS scores were lower in the study group than those in the control group, at $6,12,24,48$ and $72 \mathrm{~h}$ after operation. ${ }^{*} \mathrm{P}<0.05$, compared to the study group, indicating a statistically significant difference. VAS, Visual Analogue Scale.

groups, paired t-test for comparisons within groups, repeated measures analysis of variance for comparisons at multiple time-points (denoted by F-value), Bonferroni post hoc test for pairwise comparisons, and log-rank test for Kaplan-Meier survival analysis. $\mathrm{P}<0.05$ was considered to indicate a statistically significant difference.

\section{Results}

Baseline data. There were no statistically significant differences between the study and the control group in terms of age, sex, body mass index, preoperative $\mathrm{Hb}$, preoperative Alb, preoperative blood glucose, preoperative CRP, tumor location and tumor staging $(\mathrm{P}>0.05)$ (Table I).

Postoperative basic observation. After the operation, the first anus exhaustion time in the study group was $51.12 \pm 7.41 \mathrm{~h}$, significantly earlier than $73.18 \pm 5.83 \mathrm{~h}$ in the control group $(\mathrm{t}=19.340$, $\mathrm{P}<0.001)$. The first time getting out of bed in the study group was $37.53 \pm 8.52 \mathrm{~h}$, significantly earlier than $62.48 \pm 9.62 \mathrm{~h}$ in the control group $(\mathrm{t}=16.770, \mathrm{P}<0.001)$. The first time eating liquid food in the study group was $14.47 \pm 3.53 \mathrm{~h}$, significantly earlier than $48.53 \pm 6.23 \mathrm{~h}$ in the control group $(\mathrm{t}=43.330, \mathrm{P}<0.001)$. The first defecation time in the study group was $86.45 \pm 31.26 \mathrm{~h}$, significantly earlier than $112.74 \pm 41.24 \mathrm{~h}$ in the control group $(\mathrm{t}=4.474, \mathrm{P}<0.001)$. The time of drainage tube removal in the study group was $4.56 \pm 1.22 \mathrm{~h}$, significantly earlier than $7.21 \pm 1.73 \mathrm{~h}$ in the control group $(\mathrm{t}=11.120, \mathrm{P}<0.001)$. The time of gastric tube removal in the study group was $18.32 \pm 3.22 \mathrm{~h}$, significantly earlier than $97.72 \pm 40.17 \mathrm{~h}$ in the control group $(\mathrm{t}=19.310, \mathrm{P}<0.001)$. The time of suture removal in the study group was $7.12 \pm 1.09 \mathrm{~h}$, significantly earlier than $8.46 \pm 1.98 \mathrm{~h}$ in the control group $(\mathrm{t}=5.417, \mathrm{P}<0.001)$. The hospital stay in the study group was $9.46 \pm 0.63$ days, lower than $11.12 \pm 0.52$ days in the control group $(\mathrm{P}<0.001)$. The surgical expenses in the study group were $4.73 \pm 0.84$, lower than $5.88 \pm 0.73$ in the control group $(\mathrm{P}<0.001)$ (Table II).

Postoperative pain observation. According to pain assessment, VAS score in the study group started to decrease at $12 \mathrm{~h}$ after operation, while in the control group started to decrease at $24 \mathrm{~h}$ after operation. At $6 \mathrm{~h}$ after operation, VAS score in the study group was $2.31 \pm 0.34$, lower than $2.98 \pm 0.62$ in the control group $(\mathrm{t}=8.660, \mathrm{P}<0.05)$. At $12 \mathrm{~h}$ after operation, VAS score in the study group was $3.09 \pm 0.67$, lower than $3.87 \pm 0.88$ in the control group $(\mathrm{t}=6.207, \mathrm{P}<0.05)$. At $24 \mathrm{~h}$ after operation, VAS score in the study group was $2.83 \pm 0.85$, lower than $4.88 \pm 0.79$ in the control group $(\mathrm{t}=14.890, \mathrm{P}<0.05)$. At $48 \mathrm{~h}$ after operation, VAS score in the study group was $1.98 \pm 0.74$ lower than $2.55 \pm 0.72$ in the control group $(\mathrm{t}=4.679, \mathrm{P}<0.05)$. At $72 \mathrm{~h}$ after operation, VAS score in the study group was $1.54 \pm 0.48$, lower than 2.04 \pm 0.61 in the control group $(\mathrm{t}=5.646, \mathrm{P}<0.05)$ (Fig. 1).

Re-hospitalization rate and incidence of complications 30 days after operation. The re-hospitalization rate 30 days after operation in the study group was $3.13 \%$, lower than $13.79 \%$ in the control group $\left(\chi^{2}=6.204, \mathrm{P}=0.021\right)$. The incidence of complications 30 days after operation in the study group was $5.21 \%$, lower than $17.24 \%$ in the control group $\left(\chi^{2}=5.955\right.$, $\mathrm{P}=0.023)$. There was no statistically significant difference in the incidence of separate complications $(\mathrm{P}>0.05)$ (Table III).

QOL scores at different time-points. QOL score was compared between the two groups before nursing, at 3 and 12 months after nursing. Before nursing, there was no statistically significant difference between the study and the control group ( $\mathrm{P}>0.05)$, whereas after 3 and 12 months of nursing, QOL score was significantly higher in the study group than that in the control group $(\mathrm{P}<0.001)$. QOL scores in the two groups increased with 
Table III. Comparison of the re-hospitalization rate and incidence of complications 30 days after operation between the study and the control group [n(\%)].

\begin{tabular}{|c|c|c|c|c|}
\hline Category & Study group $(\mathrm{n}=96)$ & Control group $(\mathrm{n}=58)$ & $\chi^{2}$ & P-value \\
\hline Re-hospitalization rate & $3(3.13)$ & $8(13.79)$ & 6.204 & 0.021 \\
\hline Incidence of complications & $5(5.21)$ & $10(17.24)$ & 5.955 & 0.023 \\
\hline Gastrointestinal dysfunction & $1(1.04)$ & $3(5.17)$ & 1.079 & 0.299 \\
\hline Intestinal anastomotic fistula & $0(0.00)$ & $1(1.72)$ & 0.256 & 0.798 \\
\hline Wound infection & $4(4.17)$ & $6(10.34)$ & 1.170 & 0.242 \\
\hline
\end{tabular}

Table IV. Changes in QOL score at different time-points (mean $\pm \mathrm{SD})$.

\begin{tabular}{lccr}
\hline & \multicolumn{2}{c}{ QOL score } & \\
\cline { 2 - 4 } Time & Study group $(\mathrm{n}=96)$ & Control group $(\mathrm{n}=58)$ & $\mathrm{t}$ \\
\hline Before nursing & $65.17 \pm 5.26$ & $65.19 \pm 6.02$ & 0.025 \\
3 months after nursing & $82.77 \pm 6.21$ & $77.78 \pm 4.54$ & 5.326 \\
12 months after nursing & $91.08 \pm 6.37$ & $84.55 \pm 5.94$ & $<.980$ \\
F & 436.687 & 171.376 & $<0.001$ \\
P-value & $<0.001$ & $<0.001$ & \\
\hline
\end{tabular}

QOL, quality of life.

Table V. QOL at 3 months after nursing in the study and the control group (mean $\pm \mathrm{SD})$.

\begin{tabular}{|c|c|c|c|c|}
\hline Category & Study group $(n=96)$ & Control group $(n=58)$ & $\mathrm{t}$ & P-value \\
\hline \multicolumn{5}{|c|}{ Functional scale } \\
\hline $\mathrm{PF}$ & $88.46 \pm 2.49$ & $89.26 \pm 3.78$ & 1.583 & 0.116 \\
\hline SF & $77.45 \pm 2.35$ & $64.57 \pm 3.69$ & 26.470 & $<0.001$ \\
\hline $\mathrm{CF}$ & $93.16 \pm 2.36$ & $93.63 \pm 1.42$ & 1.373 & 0.172 \\
\hline RF & $82.13 \pm 3.24$ & $73.35 \pm 4.24$ & 14.470 & $<0.001$ \\
\hline EF & $85.74 \pm 5.45$ & $68.23 \pm 2.93$ & 22.560 & $<0.001$ \\
\hline \multicolumn{5}{|c|}{ Symptom scale } \\
\hline $\mathrm{CO}$ & $8.32 \pm 0.77$ & $11.73 \pm 1.54$ & 18.270 & $<0.001$ \\
\hline $\mathrm{PO}$ & $6.54 \pm 1.01$ & $10.23 \pm 0.69$ & 17.960 & $<0.001$ \\
\hline ID & $3.75 \pm 0.78$ & $3.26 \pm 0.98$ & 1.188 & 0.237 \\
\hline DI & $7.24 \pm 1.53$ & $12.37 \pm 1.87$ & 18.520 & $<0.001$ \\
\hline DY & $4.67 \pm 1.35$ & $4.88 \pm 1.53$ & 0.889 & 0.375 \\
\hline $\mathrm{AN}$ & $1.24 \pm 0.42$ & $1.35 \pm 0.44$ & 1.547 & 0.124 \\
\hline
\end{tabular}

QOL, quality of life; PF, physical function; SF, social function; $\mathrm{CF}$, cognitive function; RF, role function; EF, emotional function; CO, constipation; PO, poverty; ID, insomnia disorder; DI, diarrhea; DY, dyspnea; AN, anorexia.

time, and there were differences between the two groups at each time-point $(\mathrm{P}<0.001)$ (Table IV).

QOL at 3 months after nursing. At 3 months after nursing, there were statistically significant differences in SF, RF, EF, CO, $\mathrm{PO}$ and DI scores between the two groups $(\mathrm{P}<0.001)$, but no significant differences were observed in other scores $(\mathrm{P}>0.05)$.
SF score in the study group was $77.45 \pm 2.35$, higher than $64.57 \pm 3.69$ in the control group $(\mathrm{t}=26.470, \mathrm{P}<0.001)$. $\mathrm{RF}$ score in the study group was $82.13 \pm 3.24$, higher than $73.35 \pm 4.24$ in the control group $(\mathrm{t}=14.470, \mathrm{P}<0.001)$. Also, EF score in the study group was $85.74 \pm 5.45$, higher than $68.23 \pm 2.93$ in the control group $(\mathrm{t}=22.560, \mathrm{P}<0.001)$. In the symptom scale, the CO score in study group was $8.32 \pm 0.77$, lower than $11.73 \pm 1.54$ 
Table VI. QOL at 12 months after nursing in the study and the control group (mean \pm SD).

\begin{tabular}{lrrr}
\hline Category & Study group $(\mathrm{n}=96)$ & Control group $(\mathrm{n}=58)$ & $\mathrm{t}$ \\
\hline Functional scale & & & $\mathrm{P}$-value \\
PF & $97.34 \pm 2.04$ & $96.68 \pm 2.35$ & 1.836 \\
SF & $95.78 \pm 3.46$ & $87.38 \pm 2.29$ & 16.430 \\
CF & $93.96 \pm 2.89$ & $93.48 \pm 3.73$ & 0.893 \\
RF & $92.43 \pm 3.19$ & $84.15 \pm 5.28$ & 12.140 \\
EF & $96.28 \pm 2.46$ & $91.21 \pm 2.02$ & 12.230 \\
Symptom scale & & & 0.373 \\
CO & $3.45 \pm 1.21$ & $3.77 \pm 1.02$ & $<0.001$ \\
PO & $4.89 \pm 1.02$ & $5.11 \pm 0.59$ & 1.684 \\
ID & $2.33 \pm 0.48$ & $2.19 \pm 0.46$ & 1.497 \\
DI & $4.65 \pm 1.24$ & $4.76 \pm 1.39$ & 1.781 \\
DY & $3.42 \pm 1.15$ & $3.38 \pm 1.22$ & 0.001 \\
AN & $0.87 \pm 0.24$ & $0.91 \pm 0.26$ & 0.136 \\
& & & 0.074 \\
\end{tabular}

QOL, quality of life; PF, physical function; SF, social function; $\mathrm{CF}$, cognitive function; RF, role function; EF, emotional function; $\mathrm{CO}$, constipation; PO, poverty; ID, insomnia disorder; DI, diarrhea; DY, dyspnea; AN, anorexia.

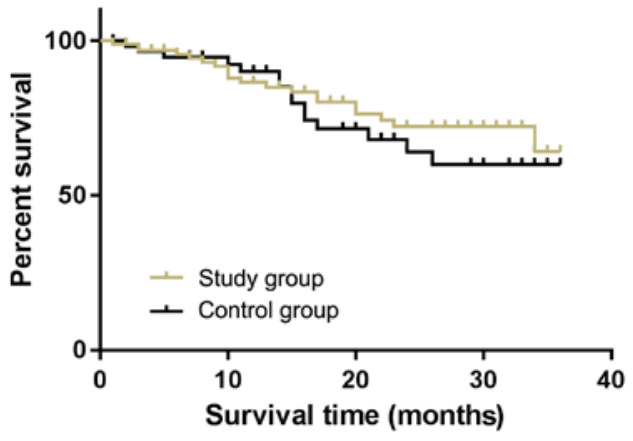

Figure 2. Comparison of the survival rates between the study and the control group. An interview at 36 months was carried out on patients of the two groups. The 3 -year OS was $64.58 \%$ in the study group, and $62.07 \%$ in the control group, with no significant difference between them $\left(\chi^{2}=0.552\right.$, $\mathrm{P}=0.458)$. OS, overall survival.

in the control group $(\mathrm{t}=18.270, \mathrm{P}<0.001)$. PO score in the study group was $6.54 \pm 1.01$, lower than $10.23 \pm 0.69$ in the control group ( $\mathrm{t}=17.960, \mathrm{P}<0.001)$. Also, DI score in the study group was $7.24 \pm 1.53$, lower than $12.37 \pm 1.87$ in the control group $(\mathrm{t}=18.520, \mathrm{P}<0.001)($ Table $\mathrm{V})$.

QOL at 12 months after nursing. At 12 months after nursing, there were statistically significant differences in SF, RF, and EF scores between the two groups $(\mathrm{P}<0.001)$, but no significant differences in any other score $(\mathrm{P}>0.05)$. SF score in the study group was $95.78 \pm 3.46$, higher than $87.38 \pm 2.29$ in the control group $(\mathrm{t}=16.430, \mathrm{P}<0.001)$. RF score in the study group was $92.43 \pm 3.19$, higher than $84.15 \pm 5.28$ in the control group $(\mathrm{t}=12.140, \mathrm{P}<0.001)$. Also, EF score in the study group was $96.28 \pm 2.46$, higher than $91.21 \pm 2.02$ in the control group $(\mathrm{t}=12.230, \mathrm{P}<0.001)$ (Table VI).

Survival of the study and the control group. An interview at 36 months was carried out on patients in the study and control groups. The 3 -year OS was $64.58 \%$ in the study group and $62.07 \%$ in the control group, with no significant difference between them $\left(\chi^{2}=0.552, \mathrm{P}=0.458\right)$ (Fig. 2$)$.

\section{Discussion}

As a common tumor disease with a high incidence and mortality rate, CRC seriously affects human health (20). It is treated with surgical resection assisted by radiotherapy and chemotherapy (21). This treatment improves the local control rate and overall survival rate and prolongs the life span of patients, but it also aggravates toxic and other side-effects because of its diversification (16), and also affects QOL for a long time. In recent years, QOL is increasingly valued by people. At present, the treatment of cancer has changed from the improvement of operative effects and survival rate to the prolongation of survival, improvement of QOL and reduction of psychological burden and adverse reactions (22). Postoperative rehabilitation is influenced by various factors. Routine surgical concept is limited because it reduces the surgical stress and improves clinical efficacy of patients with CRC only from the perspective of surgery, ignoring mental health and QOL and, fails to meet the demands for surgical nursing (23).

FTS, a new surgical nursing model that has been widely used in the nursing of gynecology, orthopedics and general surgery (24), refers to nurses, anesthesiologists, patients' relatives, surgeons, dietitians and rehabilitation therapists cooperating to minimize stress response during the perioperative period, promote postoperative rehabilitation, and reduce hospital stay and expenses (25). According to FTS concept, psychological nursing is feasible during the perioperative period because it promotes clinical treatment. Before operation, most surgical patients suffer from anxiety, fear, nervousness and other psychological disorders, which interfere with anesthesia and operation, and thereby affect clinical efficacy. Psychological intervention in patients undergoing laparoscopy 
during the perioperative period eliminates the nervousness and fear of operation, reduces psychological burden and improves the tolerance to operation and anesthesia (26).

Compared with routine surgical concept, FTS concept is superior during and after operation, which allows for the selection of the combination of short-acting anesthetics and excludes opioid anesthetics. Opioid anesthetics have a strong analgesic effect, but they affect gastrointestinal motility and intestinal secretion, thereby resulting in slow colonic transit and inhibition of defecation reflex (27), which is not conducive to postoperative rehabilitation. According to routine surgical concept, patients with CRC should be orally administered with laxative and subjected to clean enema before operation. However, according to a study, bowel preparation is not beneficial to patients undergoing CRC surgery, which may even increase the incidence of postoperative intestinal anastomotic leak (28). According to FTS concept, the removal of urethral catheter and drainage tube on the 2 nd day after operation reduces patients' psychological burden and infection rate of wounds. Preoperative fasting and water deprivation for a long time causes thirst, hunger, anxiety, hypoglycemia and hypotension (29). According to FTS concept, $500 \mathrm{ml}$ of $10 \%$ oral glucose taken orally at $2 \mathrm{~h}$ before operation effectively reduces postoperative insulin resistance and preoperative hunger and psychological pressures. According to Ding et al (30), FTS nursing reduces the incidence of complications, shortens hospital stay, and improves nursing satisfaction of patients with CRC. This is similar to our findings. FTS concept is believed to provide systematic and comprehensive nursing for patients, which is conducive to recovery.

In this study, the first anus exhaustion time, the first time getting out of bed, the first time eating liquid food, the first defecation time, time of drainage tube removal, time of gastric tube removal, time of suture removal, hospital stay and surgical expenses in the study group were shorter than those in the control group $(\mathrm{P}<0.001)$, indicating that compared with the routine surgical concept, patients with CRC receiving FTS have more stable vital signs, shorter hospital stay, less surgical expenses, lower hospital expenses and faster recovery. At $12 \mathrm{~h}$ after operation, VAS score was the highest in the study group, and then gradually decreased. Also, VAS scores were lower in the study group than those in the control group at 6 , $12,24,48$ and $72 \mathrm{~h}$ after operation $(\mathrm{P}<0.05)$, indicating that FTS concept for the nursing of patients with $\mathrm{CRC}$ can reduce pain. The re-hospitalization rate and incidence of complications 30 days after operation were lower in the study group than those in the control group $(\mathrm{P}<0.05)$, suggesting that FTS concept for the nursing of patients with $\mathrm{CRC}$ can reduce the incidence of postoperative complications, conducive to postoperative recovery. According to QOL evaluation, before operation there were no significant differences between the two groups $(\mathrm{P}>0.05)$. The QOL scores in the study group were significantly higher than those in the control group at 3 and 12 months after nursing $(\mathrm{P}<0.05)$, indicating that the FTS concept can better restore patients' social function and reduce gastrointestinal dysfunction. FTS concept for the nursing of patients in the long run is beneficial to their behavioral activities.

In conclusion, effectively improving patients' psychological state, reducing complications and improving pain, the
FTS concept during the perioperative period of CRC surgery promotes postoperative rehabilitation, reduces economic pressures and improves QOL. Therefore, the safe, feasible FTS concept with good efficacy is an effective perioperative management model, and is worthy of clinical promotion.

\section{Acknowledgements}

Not applicable.

\section{Funding}

No funding was received.

\section{Availability of data and materials}

The datasets used and/or analyzed during the current study are available from the corresponding author on reasonable request.

\section{Authors' contributions}

FX and PY were responsible for the routine surgical concept nursing. PY drafted the manuscript. FX and LL were responsible for the analysis of the observation indicators. All authors read and approved the final manuscript.

\section{Ethics approval and consent to participate}

The study was approved by the Ethics Committee of The Central Hospital of Wuhan, Tongji Medical College, Huazhong University of Science and Technology (Wuhan, China). Patients who participated in this research had complete clinical data. Signed informed consents were obtained from the patients or the guardians.

\section{Patient consent for publication}

Not applicable.

\section{Competing interests}

The authors declare that they have no competing interests.

\section{References}

1. Ren XL, He GY, Li XM, Men H, Yi LZ, Lu GF, Xin SN, Wu PX, Li YL, Liao WT, et al: MicroRNA-206 functions as a tumor suppressor in colorectal cancer by targeting FMNL2. J Cancer Res Clin Oncol 142: 581-592, 2016.

2. Leufkens AM, Van Duijnhoven FJ, Boshuizen HC, Siersema PD, Kunst AE, Mouw T, Tjønneland A, Olsen A, Overvad K, Boutron-Ruault MC, et al: Educational level and risk of colorectal cancer in EPIC with specific reference to tumor location. Int J Cancer 130: 622-630, 2012

3. Goldvaser H, Purim O, Kundel Y, Shepshelovich D, Shochat T, Shemesh-Bar L, Sulkes A and Brenner B: Colorectal cancer in young patients: Is it a distinct clinical entity? Int J Clin Oncol 21: 684-695, 2016.

4. Zheng Y and $\mathrm{Wu} \mathrm{C}$ : Prevalence and trend of gastrointestinal malignant tumors in the elderly over 75 years old in China] Zhonghua Wei Chang Wai Ke Za Zhi 19: 481-485, 2016 (In Chinese).

5. Lloyd SC: Methods and systems for improving the prevention of colorectal cancer. US Patent US 2014/0323802A1. Filed March 10, 2014; issued October 30, 2014. 
6. Alam DW and Amin A: Quality of life and well-being ranking of selected districts of Khyber Pakhtunkhwa, Pakistan. Soc Indic Res 137: 1-11, 2018.

7. Frass M, Friehs H, Marosi C, Zedtwitz-Liebenstein K and Zielinski C: Life quality and subjective feeling with additional homeopathic treatment in cancer patients. Eur J Integr Med 1: 223-224, 2009.

8. Kaseda Y, Ikeda J, Sugihara K and Kohriyama T: The therapeutic effects of low-frequency rTMS on hand function and quality of life in chronic stroke patients relating to functional integrity of the corticospinal tract. J Neurol Sci 381 (Suppl): 600, 2017.

9. Nowinski CJ, Siderowf A, Simuni T, Wortman C, Moy C and Cella D: Neuro-QoL health-related quality of life measurement system: Validation in Parkinson's disease. Mov Disord 31: 725-733, 2016.

10. Temporelli PL and Giannuzzi P: Cardiac rehabilitation after cardiac surgery: A valuable opportunity that should not be missed Eur J Cardiovasc Prev Rehabil 15: 128-129, 2008

11. Jia W, Liu W and Qiao X: Chinese expert consensus on enhanced recovery after hepatectomy (version 2017). Asian J Surg 42 $11-18,2019$.

12. Robbins CE, Casey D, Bono JV, Murphy SB, Talmo CT and Ward DM: A multidisciplinary total hip arthroplasty protocol with accelerated postoperative rehabilitation: Does the patient benefit? Am J Orthop (Belle Mead NJ) 43: 178-181, 2014.

13. Zhang YG, Zhu G, Zhu SC, Liu M, Zhang YQ, Jin B, Wei D, Wan B and Wang JY: Comparison of natural orifice transumbilical endoscopic surgery versus conventional laparoscopic surgery in renal cyst deroofing. Zhonghua Yi Xue Za Zhi 92: 276-278, 2012 (In Chinese).

14. Laudicella M, Walsh B, Munasinghe A and Faiz O: Impact of laparoscopic versus open surgery on hospital costs for colon cancer: A population-based retrospective cohort study. BMJ Open 6: e012977, 2016

15. Young PE, Womeldorph CM, Johnson EK, Maykel JA, Brucher B Stojadinovic A, Avital I, Nissan A and Steele SR: Early detection of colorectal cancer recurrence in patients undergoing surgery with curative intent: Current status and challenges. J Cancer 5: 262-271, 2014

16. Patel S, Lutz JM, Panchagnula U and Bansal S: Anesthesia and perioperative management of colorectal surgical patients - A clinical review (part 1). J Anaesthesiol Clin Pharmacol 28 162-171, 2012.

17. Du YP, Li LL, He Q, Li Y, Song H, Lin YJ and Peng JS: Nutritional risk screening and nutrition assessment for gastrointestinal cancer patients. Zhonghua Wei Chang Wai Ke Za Zhi 15: 460-463, 2012 (In Chinese).

18. Bao Y, Lyu G, Shao L, Sun X, Cao X, Wang L, Zhu C, Jia J: Influence of Jianpi Tiaogan Wenshen Recipe on abdominal pain Visual Analogue Score (VAS) and defecation of patients with diarrhea-predominant irritable bowel syndrome. Chin Arch Trad Chin Med 3: 650-652, 2015 (In Chinese).
19. Gamal RM, Mahran SA, Abo El Fetoh N and Janbi F: Quality of life assessment in Egyptian rheumatoid arthritis patients: Relation to clinical features and disease activity. Egypt Rheumatol 38: 65-70, 2016.

20. Ress AL, Perakis S and Pichler M: MicroRNAs and colorectal cancer: Cancer. In: microRNA: Cancer - From Molecular Biology to Clinical Practice. Gaetano S (ed). Springer International Publishing, Switzerland, pp89-103, 2015.

21. Ahmed S, Johnson K, Ahmed O and Iqbal N: Advances in the management of colorectal cancer: From biology to treatment. Int J Colorectal Dis 29: 1031-1042, 2014.

22. Schrom T, Horenburg L, Holz S and Paschen C: Evaluation of quality of life following prosthetic replacement of the auricle. HNO 58: 134-141, 2010 (In German).

23. Cheng Y, Jiang ZS, Xu XP, Zhang Z, Xu TC, Zhou CJ, Qin JS, He GL, Gao Y and Pan MX: Laparoendoscopic single-site cholecystectomy vs three-port laparoscopic cholecystectomy: A large-scale retrospective study. World J Gastroenterol 19: 4209-4213, 2013

24. Shao Z, Jin G, Ji W, Shen L and Hu X: The role of fast-track surgery in pancreaticoduodenectomy: A retrospective cohort study of 635 consecutive resections. Int J Surg 15: 129-133, 2015.

25. Zhang LY, Liu ZJ, Shen L and Huang YG: Application of cardiopulmonary exercise testing in enhanced recovery after surgery. Zhongguo Yi Xue Ke Xue Yuan Xue Bao 39: 831-835, 2017 (In Chinese).

26. Hawasli A, Kandeel A and Meguid A: Single-incision laparoscopic cholecystectomy (SILC): A refined technique. Am J Surg 199: 289-293; discussion 293, 2010.

27. Khansari M, Sohrabi M and Zamani F: The useage of opioids and their adverse effects in gastrointestinal practice: A review. Middle East J Dig Dis 5: 5-16, 2013.

28. Zhuang Y: Cause analysis and treatment of 17 cases of low rectal cancer postoperative anastomotic fistula. Chin Commun Doc 34: 50-51, 2014 (In Chinese).

29. Huang F, Liu SC, Shih SM, Tao YH, Wu JY, Jeng SY and Chang P: Reducing the anxiety of surgical patient's families access short message service. AMIA Annu Symp Proc 2006: 957, 2006.

30. Ding SN, Pan HY and Zhang JG: Reevaluation of the methodological quality in meta-analyses of accelerated rehabilitation on recovery after surgery for colorectal cancer. Zhonghua Yi Xue Za Zhi 97: 749-754, 2017 (In Chinese).

(i) $\Theta$ This work is licensed under a Creative Commons Attribution-NonCommercial-NoDerivatives 4.0 International (CC BY-NC-ND 4.0) License. 